\title{
Physical and electrochemical properties of mixed electrolyte 1-ethyl-3-methylimidazolium Bis(trifluoromethanesulfonyl)imide and ethylene carbonate as electrolytes for Li-ion batteries
}

\author{
Linh Thi-My Le ${ }^{1}$, Thanh Duy Vo ${ }^{2}$, Hoang Van Nguyen ${ }^{1}$, Quan Phung ${ }^{1}$, Man Van Tran ${ }^{1,2}$, Phung My-Loan Le ${ }^{1,2, *}$
}

${ }^{1}$ Department of Physical Chemistry, Faculty of Chemistry, VNUHCMUniversity of Science

${ }^{2}$ Key laboratory of Applied Physical Chemistry (APCLAB),

VNUHCM-University of Science

\section{Correspondence}

Phung My-Loan Le, Department of Physical Chemistry, Faculty of Chemistry, VNUHCM- University of Science

Key laboratory of Applied Physical Chemistry (APCLAB),

VNUHCM-University of Science

Email: Imlphung@hcmus.edu.vn

History

- Received: 21 Oct 2018

- Accepted: 01 Feb 2019

- Published: 25 Feb 2019

DOI :

https://doi.org/10.32508/stdj.v22i1.837

\section{Check for updates}

\section{Copyright}

(๑) VNU-HCM Press. This is an openaccess article distributed under the terms of the Creative Commons Attribution 4.0 International license.

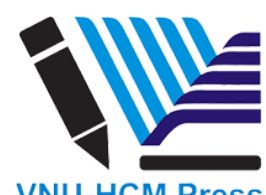

\begin{abstract}
Introduction: Ionic liquids (ILs) have become a prospective candidate to replace the conventional electrolytes based on the volatile organic-solvents in lithium-ion batteries. However, the drawbacks of high viscosity and low ionic conductivity have restricted the high rate capacity and energy density in practical batteries. With the aims to resolve these problems and design a safe electrolytes with high electrochemical stability, mixtures of ionic liquid 1-ethyl-3-methylimidazolium bis(trifluoromethanesulfonyl) imide (EMITFSI) with different amounts of ethylene carbonate (EC) was prepared and characterized as electrolytes for Li-ion batteries. Methods: In this work, we investigated four factors to demonstrate the performance of EMITFSI as electrolytes for Li-ion batteries. These factors include: thermal properties of mixed electrolytes (Mettler Toledo DSC1 Star -DSC, Q500-TGA), Conductivity (HP- AC impedance spectroscopy), Viscosity (Ostwald viscometer CANNON) and electrochemical window (cyclic voltammetry-MGP2 Biologic Instrument). All experiments were repeated three times with the exception of TGA-DSC methods. Results: The study indicated that $20 \%$ wt. ethylene carbonate (EC) when mixed with EMITFSI could significantly decrease the electrolyte viscosity while improving ionic conductivity and maintain similar electrochemical stability as pure ionic liquid. Lithium diffusion coefficient of mixed electrolytes was lower than commercial electrolytes based on conventional solvents, however, the thermal stability was enhanced. Conclusion: EMITFSI can be used to replace conventional carbonate-based liquids as a high-performance electrolyte for Li-ion batteries.

Key words: EC, EMITFSI, ionic conductivity, ionic liquid, Li-ion batteries
\end{abstract}

\section{INTRODUCTION}

Rechargeable lithium-ion battery (LIB) plays a vital role in storage technologies (EES) due to the high energy density and voltage. Nowadays, LIBs have been extensively used not only in the field of handheld electronics but also in electric vehicles and large stationary applications ${ }^{1}$. Therefore, the command for LIBs will increase electrode-material cost, while lithium resource is limiting. Besides, concerns about the safety problems have limited the commercialization of lithium batteries in mobile market, opposing the requirement of batteries. As a result, studies have been focused on redesigning electrolytes rather than improving safety ${ }^{2,3}$.

Ethylene carbonate (EC) is widely used as an effective membrane forming agent to protect the electrolyteelectrolyte interface in lithium-ion batteries. The electrolyte deactivation during the initial charging process produces a thin film called a solid electrolyte interface (SEI) on the electrode surface, which continuously prevents the depth reduction of electrolyte next to electrode structure. Due to the high flash point and high viscosity, EC should be combined with other carbonates to obtain the optimal electrolytes ${ }^{4-6}$.

In recent years, ionic liquid electrolytes have been included in lithium batteries because of its nonflammable, low-moisture steaming, and high thermal stability characteristics. Different types of ionic liquids are currently adulterated with other substances such as electrolytes, which are safe for use on various electrode materials with good compatibility. These mixtures stabilize the SEI layer to avoid a continuous reduction in electrolytes ${ }^{4-8}$. However, high viscosity remains a major problem in high-rate and hightemperature tests. In our previous report, the viscosity, conductivity as well as the electrochemical stability were improved considerably by using $20 \%$ vol. EC in electrolyte mixtures ${ }^{9}$.

In this work, mixed electrolytes based on 1-ethyl-3-methylimidazolium bis(trifluoromethanesulfonyl)imide (EMITFSI) and different amounts of EC were prepared in gloveboxes to obtain the homogenous, water- and

Cite this article : Thi-My Le L, Duy Vo T, Van Nguyen H, Phung Q, Van Tran M, My-Loan Le P. Physical and electrochemical properties of mixed electrolyte 1-ethyl-3-methylimidazolium Bis(trifluoromethanesulfonyl)imide and ethylene carbonate as electrolytes for Li-ion batteries. Sci. Tech. Dev. J.; 22(1):128-135. 
moist-free solution. The physical chemical properties (thermal stability, viscosity, ionic conductivity) and electrochemical oxidation stability were investigated to determine the suitable electrolyte composition for using in the lithium-ion batteries.

\section{EXPERIMENTAL}

\section{Preparation of electrolytes}

The chemical reagents including 1-alkyl-3methylimidazolium bis(trifluorormethanesulfonyl) imide ionic liquids (EMITFSI), lithium bis(trifluoromethanesulfonyl)imide (LiTFSI) and EC from Sigma-Aldrich were stored in a controlled argon dry box with a humidity content below $5 \mathrm{ppm}$ to avoid any contamination. Ionic liquid-based electrolytes were obtained by mixing different amounts $(5,10,15,20$ and $25 \%$ vol.) of EC into EMITFSI and $1 \mathrm{M}$ LiTFSI. These mixtures were continuously stirred with a magnetic paddle for 24 hours to ensure homogeneity.

\section{Thermal analysis}

Differential Scanning Calorimetry (DSC) measurements were performed on Mettler Toledo DSC1 Star. To be more precise, signals were recorded from $-80{ }^{\circ} \mathrm{C}$ to $100{ }^{\circ} \mathrm{C}$ at a heating rate of $10^{\circ} \mathrm{C} \cdot \mathrm{min}^{-1}$. Thermogravimetric analysis (TGA) measurements were carried out in a TGA Q500 V20.10 Build at a scan rate of $10{ }^{\circ} \mathrm{C} \cdot \mathrm{min}^{-1}$ from room temperature up to $600{ }^{\circ} \mathrm{C}$. All samples were measured with stable Nitrogen flow in a temperature-control chamber.

\section{Physical analysis}

The ionic conductivity measurements were carried by the AC impedance spectroscopy using an HP 4192A impedance analyzer in the frequency range $5 \mathrm{~Hz}-$ $13 \mathrm{MHz}$, dipping in the solutions a test cell with platinized platinum blocking electrodes and known cell constant. All the measurements were performed in a temperature range from $10^{\circ} \mathrm{C}$ to $60^{\circ} \mathrm{C}$. Before each measurement, cells were kept at a constant temperature for one day and calibrated to reach thermal equilibration. The cell constant was determined by using a $0.01 \mathrm{M} \mathrm{KCl}$ solution.

The Ostwald viscometer CANNON was used for viscosity measurement of electrolytes, which was prepared in a glove box in a temperature-controlled bath. All measurements were repeated three times to certain accuracy.

The temperature dependence of the electrical conductivity for all measured ILs can be fitted using a VogelTamman-Fulcher (VTF) type equation to obtain the activation energy. It is common for researchers to utilize the Vogel-Tammann-Fulcher (VTF) equation as a means to separate the effects of charged carrier concentration, which is often related to the pre-factor, $\mathrm{A}$, and segmental motion, which is related to the activation energy, $\mathrm{E}_{a}$, on the overall conductivity, $\sigma$, at a given temperature $\mathrm{T}^{10}$.

$\mathrm{T}_{o}$ in this equation is referred to as the Vogel temperature, equal to the glass transition in ideal glasses ${ }^{11}$, but typically taken as $50^{\circ} \mathrm{C}$ below the glass transition temperature in several electrolytes.

\section{Electrochemical analysis}

Cyclic voltammetry (CV) is one of the electrochemical techniques to study the oxidation - reduction stability of mixed electrolytes. The measurements were performed in triplicates at the scan rate of $1 \mathrm{mV} . \mathrm{s}^{-1}$ recorded on MGP2 Biologic Instrument (France) by using a standard three-electrode cell. The working electrode was a Pt micro-electrode with a diameter of $25 \mu \mathrm{m}$ and the counter electrode was a Pt wire. The reference electrode was a silver wire maintained in $\mathrm{AgNO}_{3} 10 \mathrm{mM}$ in acetonitrile $+0.1 \mathrm{M}$ tetrabutylammonium perchlorate (TBAP).

\section{RESULT}

Table 1showed featured thermal and physicochemical properties of different electrolytes. The melting point $\left(\mathrm{T}_{m}\right)$ of pure EMI-TFSI was $-33.5{ }^{\circ} \mathrm{C}$ due to the combination of low symmetry and a large size cation with low symmetry and a relatively large size anion. Owing to the melting state at low temperature, EMI-TFSI recrystallized at $-18.5^{\circ} \mathrm{C}\left(\mathrm{T}_{c}\right)$ in the cooling down step. When mixing with different ratios of EC, thermal properties as well as other physicochemical properties of ionic liquids changed significantly. The lowest $\mathrm{T}_{m}, \mathrm{~T}_{c}$ were obtained at $15 \% \mathrm{vol}$. EC mixed in EMITFSI. Additionally, crystalline point of pure EMI-TFSI was not detected at $15 \%$ wt. EC. The mixtures with different EC underwent 2 stages of decomposition while the pure stable exhibited only one degradation step at about $415^{\circ} \mathrm{C}$ (Figure 2and Table 1). The first step corresponded to the vaporization of based-carbonate organic solvents and the second step associated with the degradation of pure ionic liquid. When mixing with ionic liquid, due to the fact that the interaction between dipole - ions was much stronger than dipole - dipole, EC in mixtures evaporated more slowly than in pure state. Furthermore, with the addition of LiTFSI salt, the evaporation temperature of the EC increased, suggesting that the free ECs were partially bonded to the $\mathrm{Li}^{+}$cations or TFSI anions contained in the mixture, leading to free ECs 
Table 1: Physicochemical properties of EMI-TFSI and EMI-TFSI + $x \%$ EC at roomtemperature

\begin{tabular}{|c|c|c|c|c|c|c|}
\hline IL + LiTFSI & $\begin{array}{l}\text { Crystalline } \\
\text { point } \mathrm{Tc} \\
\left({ }^{\circ} \mathrm{C}\right)\end{array}$ & $\begin{array}{l}\text { Melting } \\
\text { point Tm } \\
\left({ }^{o} \mathrm{C}\right)\end{array}$ & $\begin{array}{l}\text { Degradation } \\
\text { point } \mathrm{Td}\left({ }^{\circ} \mathrm{C}\right)\end{array}$ & $\begin{array}{l}\text { Conductivity } \\
\left(10^{-3} \cdot \mathrm{cm}^{-1}\right)\end{array}$ & $\begin{array}{l}\text { Viscosity } \\
\text { (mPa.s) }\end{array}$ & $\begin{array}{l}\text { Density } \\
(\text { g.cm } \\
-3)\end{array}$ \\
\hline EMI-TFSI & -18.5 & -33.5 & 414.2 & 9.1 & 24.9 & 1.477 \\
\hline $\begin{array}{l}\text { EMI-TFSI+5 \%vol. } \\
\text { EC }\end{array}$ & -20.5 & -36.6 & - & 6.9 & - & - \\
\hline $\begin{array}{l}\text { EMI-TFSI+10 \%vol. } \\
\text { EC }\end{array}$ & -28.4 & -38.8 & $266.7 / 492.9$ & 13.5 & - & - \\
\hline $\begin{array}{l}\text { EMI-TFSI+15 \%vol. } \\
\text { EC }\end{array}$ & -29.7 & -42.4 & $252.6 / 489.5$ & 14.1 & - & - \\
\hline $\begin{array}{l}\text { EMI-TFSI+ } 20 \text { \%vol. } \\
\text { EC }\end{array}$ & - & - & $248.5 / 485.6$ & 15.8 & 14.1 & 1.508 \\
\hline $\begin{array}{l}\text { EMI-TFSI + } 0.5 \mathrm{M} \\
\text { LiTFSI }\end{array}$ & - & - & 431.5 & 6.1 & 44.7 & 1.580 \\
\hline $\begin{array}{l}\text { EMI-TFSI + } 20 \% \text { vol. } \\
\text { EC + } 0.5 \text { M LiTFSI }\end{array}$ & - & - & $249.0 / 487.7$ & 10.0 & 24.6 & 1.592 \\
\hline
\end{tabular}

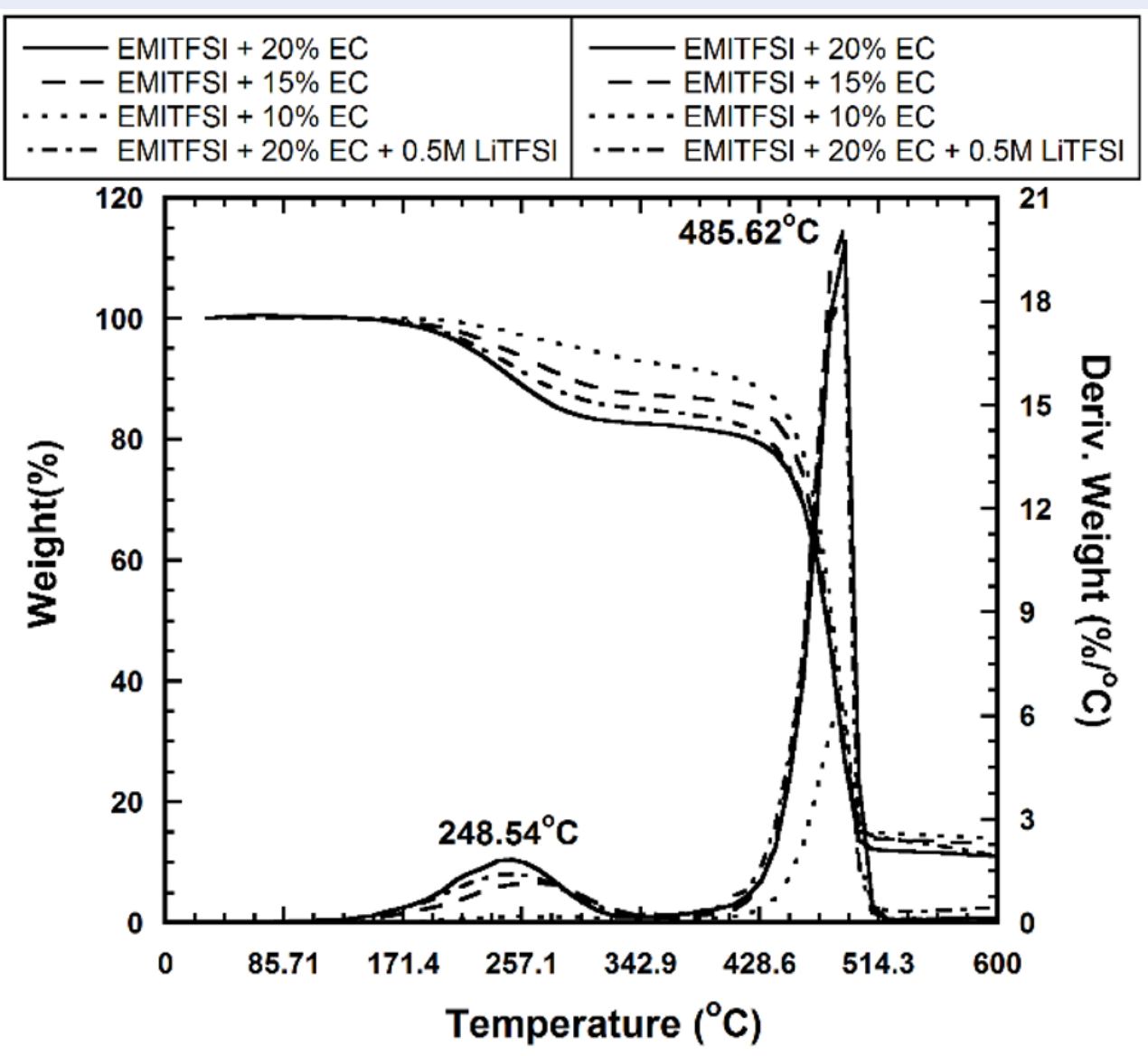

Figure 1: TGA diagrams of EMITFSImixed with different percentages of ethylene carbonate. 


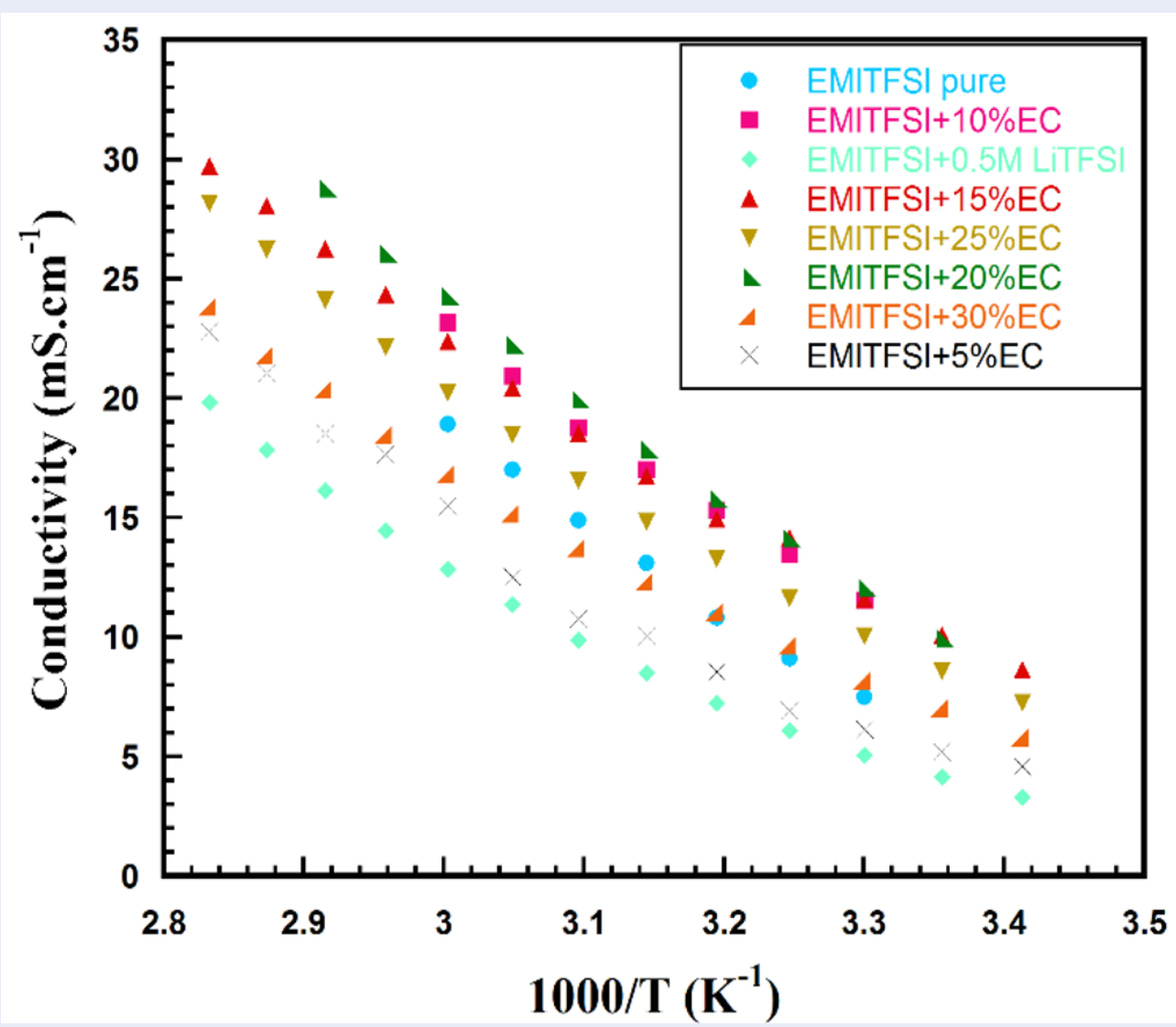

Figure 2: The conductivity of mixed electrolytes follows the temperature: EMITFSI + $x$ \%vol.EC, EMITFSI + 0.5 M LiTFSI.

being held tightly in electrolyte solutions due to solvation sphere $\mathrm{Li}^{+}$-EC or TFSI ${ }^{-}$- EC.

As viscosity is a drawback of ionic liquids, it was attempted to reduce its viscosity by using less viscous organic solvent as co-solvent. By adding EC to the ionic liquid solution, the conductivity of mixed electrolytes was slightly reduced at $5 \%$ vol. EC due to the interactions between solvent and IL, which was then increased significantly because the viscosity was much lower compared to pure ionic liquid (Table 1). On the other hand, temperature also contributed to the viscosity and conductivity values (Figure 2 ). The increase of the temperature led to the decrease of viscosity and the rise of ion movement rate, thus, leading to the enhanced conductivity to gain the best value at 20 \%vol. EC. When increasing the EC amount to more than $20 \%$ vol., the ionic conductivity decreased unexpectedly.

The temperature dependence of the conductivity exhibited a curvature typical of Vogel - Tammann - Fulcher (VTF) behavior for supercooled liquids and glasses, in which case, the mixtures EC-ILs increased with an increase of EC addition (Figure 2). However, the solution conductivity decreased unanimously when the concentrations of ionic solutes, such as $\mathrm{Li}^{+}$salt, was added. This phenomenon occurred due to the increase of viscosity.

The activation energy of EMI-TFSI has a decreased tendency with increasing EC concentration in mixtures and reached the lowest value at the $20 \%$ vol. EC; which was then followed by the rising of $\mathrm{E}_{a}$ at higher EC amount (Table 2). However, these values were 30 - $40 \%$ higher than that of other ionic liquids (quaternary ammonium based ILs, ex. $\mathrm{N}_{1123}$ TFSI and $\mathrm{N}_{1124}$ TFSI). It could be explained by the changes in cation structure and that the ring-imidazolium exhibited stronger interaction with TFSI anion than the quaternary ammonium. In addition, ion-ion electrostatic interaction with high ionic concentrations partially holds up ionic bond, which is difficult for them to be released and become non-electrical charged particles. LML. Phung et al. ${ }^{12}$ calculated the diffu- 


\begin{tabular}{|c|c|c|c|}
\hline$\%$ EC & Ea N1123TFSI ${ }^{12}$ & Ea N1124TFSI ${ }^{12}$ & Ea EMITFSI \\
\hline 5 & 1800 & 2100 & 3148 \\
\hline 10 & 1513 & 1824 & 2970 \\
\hline 15 & 1330 & 1647 & 2539 \\
\hline 20 & 1190 & 1543 & 2470 \\
\hline 25 & 972 & 1621 & 2512 \\
\hline 30 & - & - & 2743 \\
\hline
\end{tabular}

sion coefficient using pulsed Nuclear magnetic resonance technique (NMR), which showed that the conductivity values based on electrochemical method and pulsed NMR method were significantly different. This has helped to confirm the existence of nonelectric subunits (ion pairs, clusters) within the ionic liquid structure, leading to the reduced conductivity ${ }^{13}$.

In fact, when two liquids could be mixed to form an ideal solution, it means that there is no interaction between molecules, the theoretical will be calculated by equation $\operatorname{Ln}\left(\eta_{\text {mix }}\right)=X_{1} \operatorname{Ln}\left(\eta_{1}\right)+$ $X_{2} \operatorname{Ln}\left(\eta_{2}\right)^{14}$ where $\mathrm{X}_{1}, \mathrm{X}_{2}$ are $\%$ vol. of solution 1 and 2 , respectively. In the case of EC - ionic liquid mixtures, the difference between theoretical and real value was increased up to $51 \%$ (Table 3 ). These values were also compared with the other ILs $\mathrm{N}_{1123}$ TFSI and $\mathrm{N}_{1124}$ TFSI mixed with EC, $10-20 \%$. This suggests that these solutions were not ideal and the interactions of solvent with ionic liquid reduced the ion-ion interactions within molecules to increase conductivity and decrease viscosity.

Typical features of ionic liquids include large electrochemical window and high oxidation and reduction stability. EMITFSI was oxidized at about 5.25 $\mathrm{V} v s \mathrm{Li}^{+} / \mathrm{Li}$, which was less stable in oxidation compared to the conventional electrolyte, $1 \mathrm{M} \mathrm{LiPF}_{6} / \mathrm{EC}$ DMC (1:1); while $\mathrm{N}_{1123}$ TFSI and $\mathrm{N}_{1124}$ TFSI were oxidized at about $6.2 \mathrm{~V} \mathrm{vs} \mathrm{Li}^{+} / \mathrm{Li}$ (Figure 3). The cation structure of ionic liquid was responsible for oxidation current, in this case, the ring-imidazolium was less stable than the quaternary ammonium structure due to the unsaturated $\mathrm{C}=\mathrm{C}$ bonding. However, when lithium salt was added, the oxidation limit enhanced because the stability of paired ions (cation-anion) was enhanced, thus there was less "free" cations. The addition of EC into EMI-TFSI based electrolytes maintained similar oxidation potential limit as pure ionic liquid at up to $25 \%$ wt. (Figure 4).

\section{DISCUSSION}

The addition of ethylene carbonate defined a considerable impact on the thermal, physical chemical and the electrochemical properties of electrolyte-based ionic liquid. Regarding to the thermal properties, a decrease in the tendency of $\mathrm{T}_{c}, \mathrm{~T}_{m}$ along with an increase of EC could be associated with the strength of ionic liquid-intermolecular interactions, the molecular symmetry and the freedom of the molecules. Phung et al. ${ }^{12}$ reported similar phenomena when mixing EC with quaternary ammonium based-ionic liquid at different ratios from 5 to $40 \%$ vol. EC. Due to the intermolecular interaction between ionic liquids and EC molecules, the evaporation of EC in electrolyte mixtures under thermal flux was expectedly shifted to the higher temperature compared to the original flash point of pure EC. Furthermore, EC added in ionic liquid-based electrolyte exhibited a significant increase of ionic conductivity due to the dilution effect of electrolytes. The dilution of ionic environment helped to decrease the ion-ion interaction between $\mathrm{Li}^{+}$and $\mathrm{TFSI}^{-}$anion and other ions of ionic liquid. Thus, it can be assumed that $\mathrm{Li}^{+}$ion has higher mobility in EC-ILs solution compared to pure ILs. However, the addition of EC up to $25 \%$ gave rise to the opposite effect on the activation energy of conduction due to the alternative solvation of $\mathrm{Li}^{+}$ion by EC molecules, which decreased the ionic mobility by its large solvated radius. Additionally, the high amount of EC addition (> $30 \%$ vol.) penalized the electrochemical stability of ionic liquid-based electrolyte. In fact, the carbonate solvents-based electrolyte was mostly oxidized at $4.5 \mathrm{vs}^{+} / \mathrm{Li}$ while the ionic liquid could be stable up to $5.0 \mathrm{vs} \mathrm{Li}^{+} / \mathrm{Li}$. When added at low concentration, EC molecules interacted with ionic species in mixed electrolytes to form a cluster or non-electric subunits, leading to the hindering of EC signature on the oxidation curve. 
Table 3: Theoretical and realviscosity of ionic liquid mixed with different percentages of EC

\begin{tabular}{llll}
\hline \% EC & N1123TFSI ${ }^{12}$ & N1124TFSI ${ }^{12}$ & EMITFSI \\
10 & $19.8 / 15.8(\mathrm{a})$ & $23.3 / 22.1$ & $11.3 /-$ \\
15 & $13.8 / 11.1$ & $15.9 / 15.6$ & $8.6 /-$ \\
20 & $10.4 / 9.3$ & $11.7 / 12.3$ & $6.9 / 14.1$ \\
25 & $8.1 / 7.0$ & $9.0 / 10.1$ & $5.8 /-$ \\
\hline
\end{tabular}

Table 4: The oxidation and reduction values ofdifferent ILs and conventional electrolytes based on organic solvents

\begin{tabular}{llll}
\hline Solution & Eanode vs. $\mathbf{L i}+/ \mathbf{L i}(\mathbf{V})$ & Solution & Eanode vs. $\mathbf{L i + / L i}(\mathbf{V})$ \\
LiClO$^{15}$ & 4.40 & N1123TFSI & 6.20 \\
LiTFSI $^{15}$ & 4.90 & N1124TFSI & 6.20 \\
LiPF6 & 6.10 & EMITFSI & 5.25 \\
\hline
\end{tabular}

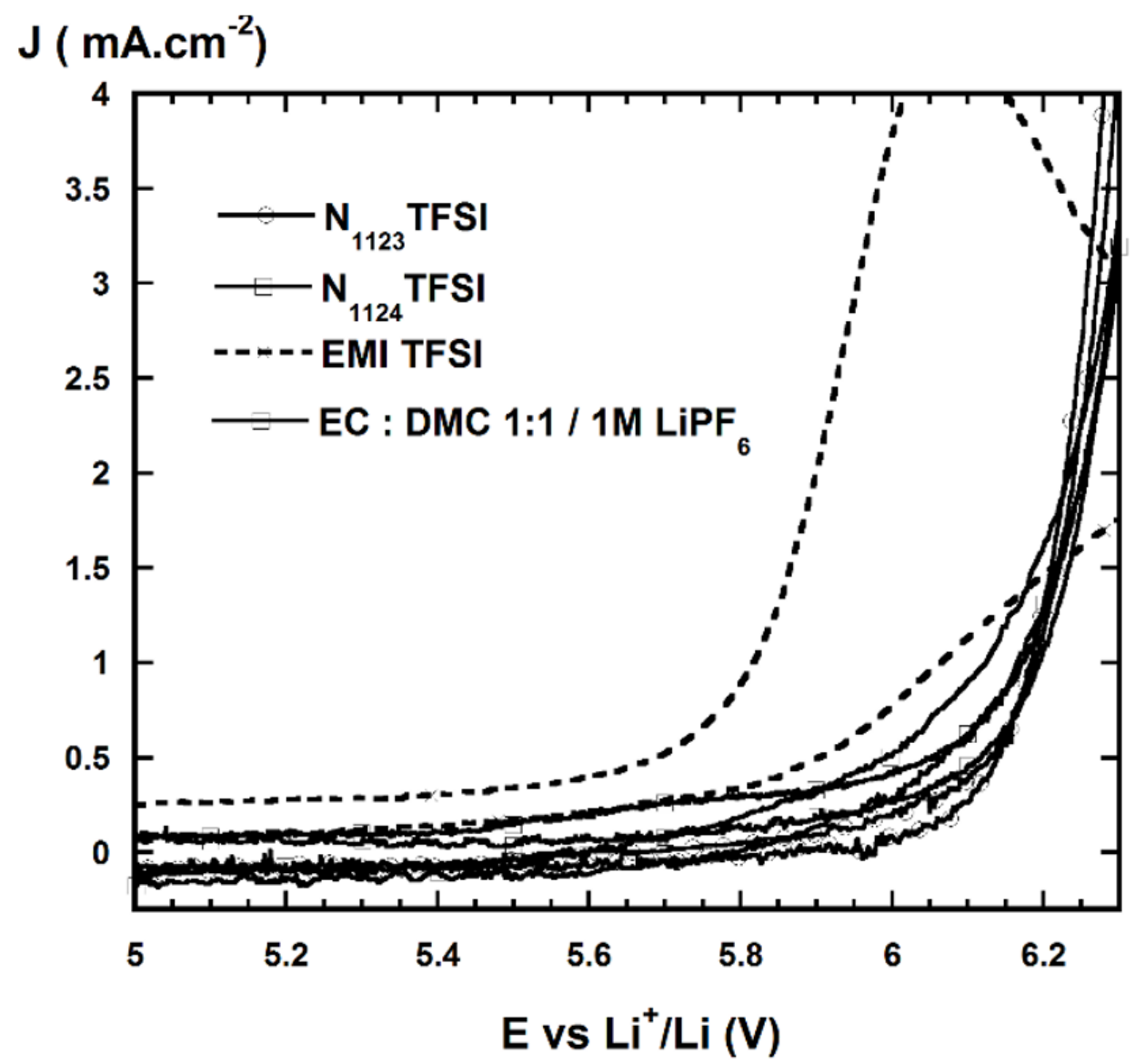

Figure 3: Cyclic voltammogram of commercialelectrolytes (lithium salt + organic solvent) and pure ILs. 


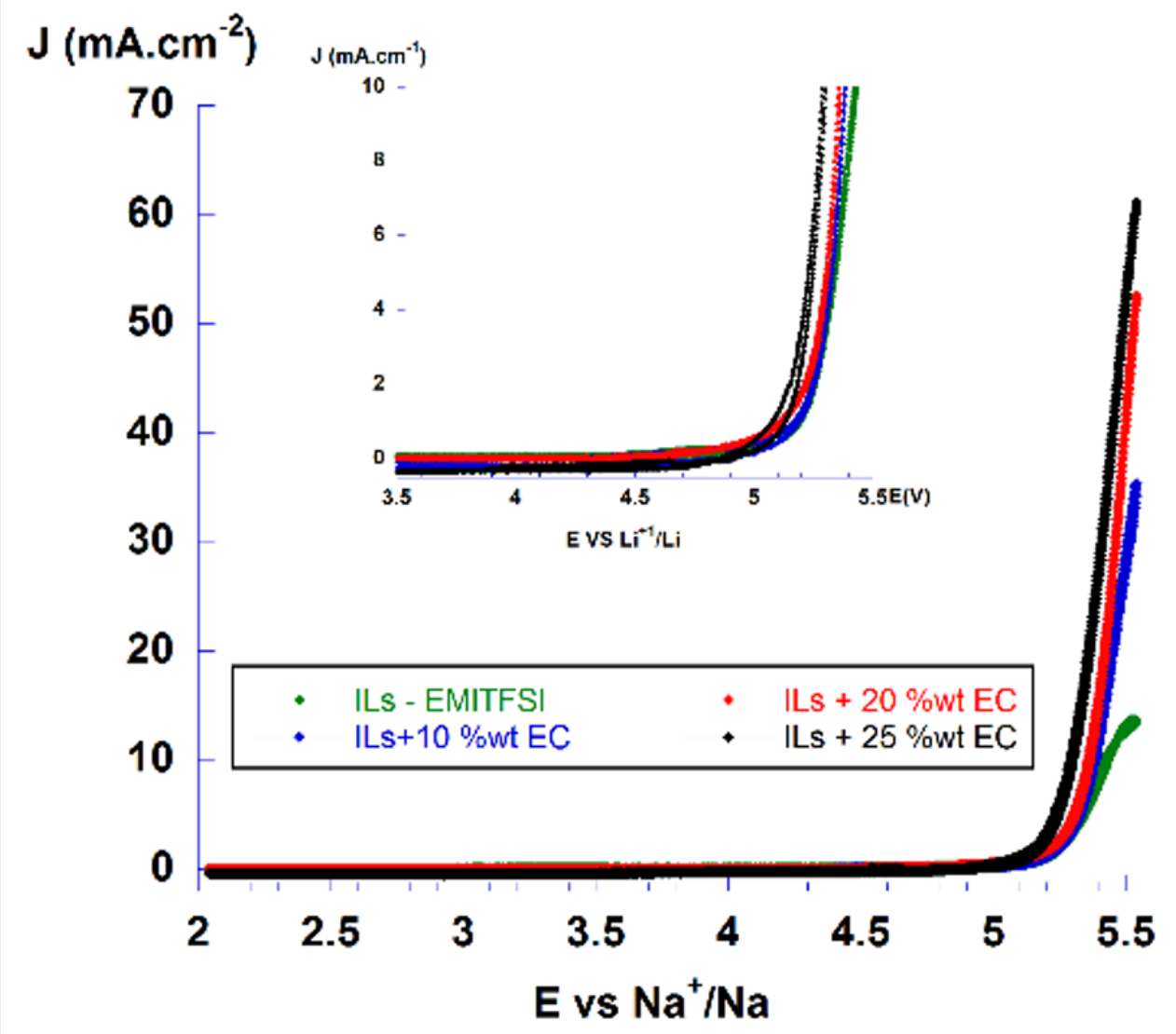

Figure 4: Cyclic voltammogram of $x \%$ wt.EC addedin EMITFSI ionic liquid.

\section{CONCLUSION AND PERSPECTIVES}

In summary, the combination of EMI-TFSI with EC is promising for reducing viscosity and enhancing ionic conductivity. The thermal stability of mixed electrolyte EMITFSI- $\mathrm{x} \%$ wt.EC was appropriate for the application in lithium-ion batteries, even at $20 \% \mathrm{wt}$. EC. In addition, the oxidation stability of mixed electrolyte EMITFSI- $\mathrm{x} \%$ vol.EC was as good as the pure ionic liquid.

To further understand the mechanism of electrolyte's operation, the stability of electrode-electrolyte interface (Solid Electrolyte Interface) as well as iondiffusion mechanism should be investigated to improve continuously actual problems in LIBs. Besides, EMITFSI is also a promising candidate for sodium ion batteries due to the similar characteristics between two types of secondary batteries, which can be aimed for the design of cheaper and safer cell in large-scale applications.

\section{ABBREVIATIONS}

EC: ethylene carbonate EMITFSI: 1-alkyl-3-methylimidazolium bis(trifluorormethanesulfonyl) imide

ILs: Ionic liquids

LiTFSI: lithium bis(trifluoromethanesulfonyl)imide TBAP: tetrabutylammonium perchlorate

\section{COMPETING INTERESTS}

The authors declare that there is no conflict of interest regarding the publication of this article.

\section{AUTHORS' CONTRIBUTIONS}

All the authors contribute equally to the paper including the research idea, experimental section and written manuscript.

\section{ACKNOWLEDGMENTS}

The authors acknowledge funding from Department of Science and Technology of Ho Chi Minh City (DOST) under the contract 135/2017/HĐ-SKHCN. 


\section{REFERENCES}

1. Mizushima K, Jones PC, Wiseman PJ, Goodenough JB. ixCoO2 $(0<x<1)$ : A new cathode material for batteries of high energy density. Materials Research Bulletin. 1980;15(6):783-9. Available from: 10.1016/0025-5408(80)90012-4.

2. van Schalkwijk W, Scrosati B. Advances in Lithium-ion Batteries Introduction; 2002. Available from: 10.1007/0-306-47508$1 \_1$.

3. Lee JS, Bae JY, Lee H, Quan ND, Kim HS, Kim H. Ionic liquids as electrolytes for $\mathrm{Li}$ ion batteries. Journal of Industrial and Engineering Chemistry. 2004;10:1086-9.

4. Marcus Y. Ionic liquid properties: From molten salts to RTILs. Springer International Publishing; 2016. Available from: 10. 1007/978-3-319-30313-0.

5. Lewandowski A, Świderska Mocek A. Ionic liquids as electrolytes for Li-ion batteries-An overview of electrochemical studies. Journal of Power Sources. 2009;194(2):601-9. Available from: 10.1016/j.jpowsour.2009.06.089.

6. Galiński M, Lewandowski A, Stepniak I. Ionic liquids as electrolytes. Electrochimica Acta. 2006;51(26):5567-80. Available from: 10.1016/j.electacta.2006.03.016.

7. Electrochemical Aspects of lonic Liquids. John Wiley \& Sons Inc; 2005. Available from: 10.1002/0471762512.

8. Yim T, Choi CY, Mun J, Oh SM, Kim YG. Synthesis and properties of acyclic ammonium-based ionic liquids with allyl substituents as electrolytes. Molecules (Basel, Switzerland). 2009;14(5):1840-51. Available from: 10.3390/ molecules 14051840 .
9. Jin Y, Fang S, Chai M, Yang L, Tachibana K, Hirano SI. Properties and application of ether-functionalized trialkylimidazolium ionic liquid electrolytes for lithium battery. Journa of Power Sources. 2013;226:210-8. Available from: 10.1016/ j.jpowsour.2012.10.076.

10. Diederichsen M, Buss G, McCloskey D. The Compensation Effect in the Vogel-Tammann-Fulcher (VTF) Equation for Polymer-Based Electrolytes. Macromolecules. 2017;50(10):3831-40. Available from: 10.1021/acs.macromol $7 \mathrm{~b} 00423$.

11. Gu GY, Bouvier S, Wu C, Laura R, Rzeznik M, Abraham KM 2-Methoxyethyl (methyl) carbonate-based electrolytes for $\mathrm{Li}$ ion batteries. Electrochimica Acta. 2000;45(19):3127-39. Available from: 10.1016/S0013-4686(00)00394-7.

12. Le ML, Cointeaux L, Strobel P, Lepre J, Judeinstein P, Alloin F. Influence of Solvent Addition on the Properties of Ionic Liquids. The Journal of Physical Chemistry C. 2012;116(14):77128. Available from: 10.1021/jp301322x.

13. Le MLP, Alloin F, Strobel P, Leprêtre JC, del Valle CP, Judeinstein P. Structure-Properties Relationships of Lithium Electrolytes Based on lonic Liquid. J Phys Chem B Jenuary. 2010;114(2):894-903.

14. Peled E, Golodnitsky D, Menachem C, Bar-Tow D. An advanced tool for the selection of electrolyte components for rechargeable lithium batteries. Journal of the Electrochemical Society. 1998;145(10):3482-6. Available from: 10.1149/1.1838831.

15. Phung LM, Alloin F, Anh TN, Khanh NH, Nguyen TG, Dan BT. Mixtures lonic Liquids-Ethylen Carbonate for Lithium Batteries and Supercapacitor.; In: Meeting Abstracts. vol. 2. The Electrochemical Society; 2015. p. 437-437. 